\title{
Characterization, optimization and classification of LM and HM-pectins from mango peel, passion fruit rinds, and Bambara groundnut shells wastes mixtures
}

\author{
RANDRIAMPENOHAJA A. R. Jens ${ }^{1-2}$, RASOLOHERY Claudine A..$^{3-4}$, RAKOTOVAO Marcelle ${ }^{5}$, \\ RASOARAHONA Jean R. E. ${ }^{1}$ \\ ${ }^{1}$ College of Agricultural Sciences (Dept. Food and Agricultural Industries) and Doctoral School for Engineering of Processes and Industrial, \\ Agricultural and Food Systems, University of Antananarivo \\ ${ }^{2}$ Ambositra Institute of Technology (Dept. of Food Process and craft Industries) \\ 3 Plant - Health Laboratory, Fianarantsoa, Madagascar \\ ${ }^{4}$ Faculty of Science, University of Fianarantsoa, Madagascar \\ ${ }^{5}$ Chemistry and Natural Products Laboratory, Faculty of Science, University \\ of Antananarivo, Madagascar
}

DOI: 10.29322/IJSRP.11.08.2021.p11616

http://dx.doi.org/10.29322/IJSRP.11.08.2021.p11616

\begin{abstract}
This study aims to characterize, to optimize, and to classify the pectins obtained from the mixtures of mango peel, passion fruit rinds, and Bambara groundnut shells wastes. A Mixture Experiments with Process Variables (MPV) design was applied. The low level of the process variables ( $\mathrm{pH}$ and liquid/solid ratio: $L S R$ ) were set at 1.5 and $12.5 \mathrm{ml} / \mathrm{g}$ respectively, the high level at 2 and $15 \mathrm{ml} / \mathrm{g}$. Citric acid was used as extracting agent in two-stepped extraction at $80^{\circ} \mathrm{C}$ and 60 minutes separately. The yield, equivalent weight (EW), methoxyl content $(\mathrm{MeO})$, anhydrouronic acid content $(A U A)$, and the degree of esterification (DE) of the 28 experimental points were determined. The yields and the qualities of the extracted pectins depended on the plant sources, the mix ratio, the $\mathrm{pH}$ and the LSR. Mango and passion fruit wastes gave good yields of pectins and high AUA contents. In contrast, Bambara groundnut waste provided moderate yield and appreciable values of $E W, M e O$ and $D E$. This complementarity created the opportunity to achieve final products that can compete commercial pectins by mixing the plant sources, particularly with Mango-Bambara groundnut (MB) mix. The use of MPV design offered the possibility of scanning pectins that meet the standard specifications at the experimental domain. Good qualities and high-yielded LM-pectin (LMP), and HM-pectins (HMP) can be extracted at the same time. The optimum yields were $40.3 \%$ for $L M P$ (MB: $31.3 \%$ - 68.7\%), $32.0 \%$ for slow set pectin (MB: $56.6 \%$ - 43.4\%), $27.5 \%$ for medium set pectin (MB: $95.0 \%-5.0 \%)$, and $19.0 \%$ for rapid set pectin (MB: $54.6 \%$ $45.4 \%)$. The presence of Bambara groundnut in the plant wastes mixtures is the key factor of the procurement of marketable pectins.
\end{abstract}

Keywords- pectin, wastes mixtures, MPV design, characterization, optimization, classification

\section{INTRODUCTION}

Pectin is a family of complex polysaccharides present within the primary cell wall and intercellular areas of dicotyledons. Pectins are methylated ester of polygalacturonic acid that contains 1,4linked-D-galacturonic acid residues [1]. This structure involves 300-1000 chains of galacturonic acid units [2]. High methoxyl pectins (HMP) have more than half the carboxyl groups as methyl esters and form gels in the presence of high sugar concentrations and acid. Low methoxyl pectins (LMP) have less than half the carboxyl groups as methyl esters [3], they form gels in presence of cations as calcium ions [4].

Most commercial pectins, commonly intended for the preparation of gelling food products, are produced from citrus (lemon, lime, orange, and grapefruit) peel and apple pomace [5-8]. On a dry weight basis, the two industrial by-products are pectin-rich sources, with a pectin content of 15-30\% (for citrus peel) and 10 $15 \%$ (for apple pomace). But, there are other commercially viable sources of pectins: sunflower head residues (for naturally LMP), sugar beet pulp (for manufacturing pectin emulsifiers), and some tropical fruit by-products such as mango peel (for HMP), yellow passion fruit rind (for naturally HMP and LMP), and cashew apple pomace (for naturally LMP) [9-10]. Passion fruit rind, for example, is used in some emerging countries such as Brazil for manufacturing marketable pectins [11].

Besides, our recent research stipulated that the mixing of the plant wastes from mango peel (Mangifera indica) recovered from fody variety, yellow variety of passion fruit rinds (Passiflora edulis) and creamy brown-striped Bambara groundnut shells (Vigna subterranea) had a significant synergetic effect on the mixes' pectin yields permitting to the procurement of high yielded-pectins [12]. However, these achieved pectins need to be characterized, the yields and the qualities of these pectins must be optimized in order to find marketable pectins fitting the standard specifications. The functional properties of pectins as well as equivalent weight (EW), methoxyl content (MeO), anhydrouronic acid (AUA) content and the degree of esterification (DE), are highly correlated to their structures, which depend on the plant sources and the extraction method used, establishing variations in the content and quality [13].

The Minitab ${ }^{\circledR}$ 18.1 Software (Minitab Inc., State College, PA, USA) provides the Mixture Experiments with Process Variables (MPV) design which allowed to fulfill the aim of this research [1415]. The polynomial models of the aforementioned physic- 
chemical parameters will be applied to predict at once the optimum yields and the optimum qualities of different categories of pectins that can be obtained from the experimental design.

\section{MATERIALS AND METHODS}

\subsection{Preparation of the plant sources}

The mango peel from fody variety, the passion fruit rinds from yellow variety, and the shells of creamy brown-striped Bambara groundnut were recuperated from the markets of Fianarantsoa, Madagascar. Immediately afterward, these wastes were treated at the LPS laboratory. After washing, sorting and weighing, they were dried in an oven at $50^{\circ} \mathrm{C}$ until constant weight. The dry wastes were then powdered with a pestle and mortar and passed through a $0.6 \mathrm{~mm}$ diameter sieve. The powders were weighed and stored individually in plastic vessels.

They were pretreated twice with $85^{\circ}$ ethanol at $70^{\circ} \mathrm{C}$ for 20 minutes under reflux to remove soluble ethanol impurities (sugars, pigments, etc.) [16]. The insoluble fractions were dried in an oven at $50^{\circ} \mathrm{C}$ and then stored in the freezer at $-18^{\circ} \mathrm{C}$ before further use.

\subsection{Experiment designs}

The Mixture Experiments with Process Variables (MPV) design [14-15], provided by Minitab® 18.1 Software (Minitab Inc., State College, PA, USA) was uses. It is an association of the simplexcentroid mixture design [17] of the 3 components (mango, passion fruit, and Bambara groundnut) illustrated in figure 1 and the full factorial design of the process variables ( $\mathrm{pH}$ and LSR) in table 1.

The full factorial design is the association of the low level (-) and the high level $(+)$ of the process variables. It contains 4 runs. The $\mathrm{pH}$ levels were fixed at 1.5 and 2 but the Liquid/Solid ratio (LSR) were set at $12.5 \mathrm{ml} / \mathrm{g}(150 \mathrm{ml} / 12 \mathrm{~g})$ and $15 \mathrm{ml} / \mathrm{g}(150 \mathrm{ml} / 10 \mathrm{~g})$. Thus, the MPV design has 28 runs (Table 2). The extraction yields, the $\mathrm{EW}$, the $\mathrm{MeO}$, the AUA content and the DE were evaluated for each experimental point. The experiments were repeated twice.

\subsection{Pectin extraction}

Pectins were extracted using citric acid and the technique of sequential two-step extraction [18]. The temperature and the extraction time were $80^{\circ} \mathrm{C}$ and 60 minutes respectively [19]. After 60 minutes, the mixtures were sieved through a polyester cloth and then cooled to room temperature. The residues were subject to a second extraction under the same conditions. The second filtrates were poured to the first ones and stored in a refrigerator at $4{ }^{\circ} \mathrm{C}$. Double volumes of $96^{\circ}$ ethanol were added to the refrigerated filtrates. They were kept for 1 hour to precipitate the pectins. The precipitates were washed twice with $70^{\circ}$ ethanol then once with $96^{\circ}$ ethanol. The purified pectins were stored at $4^{\circ} \mathrm{C}$ overnight and then dried in a $50^{\circ}$ oven until constant weight.

\subsection{Pectin yields}

Pectin yields were calculated using equation 1 .

$$
Y_{\text {pec }(\%)}=\left(\frac{P}{P_{0}}\right) \times 100
$$

Where Ypec (\%) is the pectin yield, $P$ is the weight of the pectin after drying. $P_{0}$ is the initial weight of waste powder taken individually or blended before pre-treatment with $80^{\circ}$ ethanol at $70^{\circ} \mathrm{C}$ during 20 minutes.

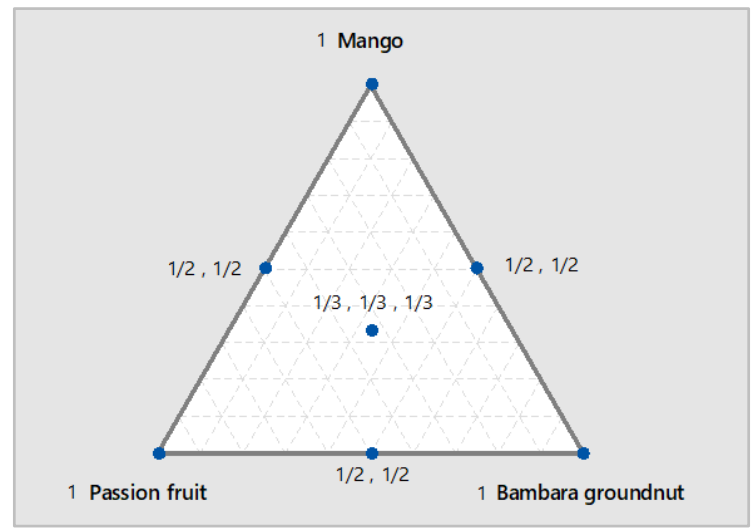

Figure 1: Simplex-centroid design of the three plants sources

Table 1: Full factorial design of the process variables

\begin{tabular}{|c|c|c|}
\hline \multicolumn{3}{|c|}{ Process variables } \\
4 runs \\
\hline Run & $\mathrm{pH}$ & LSR \\
\hline 1 & - & - \\
\hline 2 & + & - \\
\hline 3 & - & + \\
\hline 4 & + & + \\
\hline
\end{tabular}

Table 2: MPV design of the whole experiments

\begin{tabular}{|c|c|c|c|c|}
\hline & \multicolumn{4}{|c|}{ Process variables (pH*LSR) } \\
\hline Type of Mixture & 1 & 2 & 3 & 4 \\
\hline M $100 \%$ & $-\quad-$ & + & - & ++ \\
\hline P $100 \%$ & $-\quad-$ & + & - & ++ \\
\hline B $100 \%$ & $-\quad-$ & + & - & ++ \\
\hline MP $50 \%-50 \%$ & $-\quad-$ & + & & ++ \\
\hline MB $50 \%-50 \%$ & $-\quad-$ & + & & ++ \\
\hline PB 50\%- $50 \%$ & $-\quad-$ & + & - & ++ \\
\hline MPB $33.3 \%-33.3 \%-33.3 \%$ & $-\quad-$ & + & - & ++ \\
\hline
\end{tabular}

M: Mango, P: passion fruit, B: Bambara groundnut

\subsection{Equivalent weight (EW)}

Equivalent weight is used to calculate the anhydrouronic acid (AUA) content and the degree of esterification (DE) according to Owens et al. method (1952) [20]. It is assessed by titration with sodium hydroxide to $\mathrm{pH} 7.5$ using either phenol indicator. $0.5 \mathrm{~g}$ of pectin substances (ammonia and ash-free) was weighed into a 250$\mathrm{ml}$ conical flask. Then, it was diluted with $5 \mathrm{ml}$ ethanol. $1 \mathrm{~g}$ of sodium chloride was added to sharpen the end point. $100 \mathrm{ml}$ of distilled water was added together with six drops of phenol red or Hinton's indicator. All the pectin substances are made sure to have dissolved. Then, the solution was titrated slowly with $0.1 \mathrm{~N} \mathrm{NaOH}$. 
Titration point was indicated by purple color. It can be determined by the equation below.

$$
\text { Equivalent weight }=\frac{\text { Weight of sample } \times 1000}{\text { ml of alkali } \times \text { Normality of alkaly }}
$$

\subsection{Methoxyl Content (MeO)}

The methoxyl content is an important factor in controlling the setting time of pectins, the sensitivity to polyvalent cations, and their usefulness in the preparation of low solid gels, fibers and film. It is measured by saponification of the pectin and titration of the liberated carboxyl groups. Determination of $\mathrm{MeO}$ was done by using the Ranganna's method (1986) [21]. The neutral solution was collected from determination of $\mathrm{EW}$, and $25 \mathrm{ml}$ of sodium hydroxide $(0.25 \mathrm{~N})$ was added. The mixed solution was stirred thoroughly and kept at room temperature for $30 \mathrm{~min}$. After $30 \mathrm{~min}$ $25 \mathrm{ml}$ of $0.25 \mathrm{~N}$ hydrochloric acid was added and titrated against $0.1 \mathrm{~N} \mathrm{NaOH}$ to the same end point as before like in equivalent weight titration [22].

$$
\text { Methoxyl content } \%=\frac{\text { ml of alkali } \times \text { Normality of alkali } \times 31 \times 100}{\text { Weight of sample } \times 1000}
$$

Where 31 is the molecular weight of methoxyl.

\subsection{Total Anhydrouronic Acid Content (AUA)}

Estimation of AUA content is essential to determine the purity and degree of esterification, and to evaluate the physical properties. Pectin, which is a partly esterified polygalacturonide, contains $10 \%$ or more of organic material composed of arabinose, galactose and perhaps sugars. Making used of the equivalent weight and methoxyl content value of titre used. Total AUA of pectin was obtained by the following formula [23].

$$
\% \text { of } A U A=\frac{176 \times 0.1 z \times 100}{w \times 1000}+\frac{176 \times 0.1 y \times 100}{w \times 1000}
$$

Where molecular unit of AUA (1 unit) $=176 \mathrm{~g}$ Where, $\mathrm{z}=\mathrm{ml}$ (titre) of $\mathrm{NaOH}$ from equivalent weight determination.

$\mathrm{y}=\mathrm{ml}$ (titre) of $\mathrm{NaOH}$ from methoxyl content determination. $\mathrm{W}=$ weight of sample

\subsection{Determination of Degree of Esterification (DE)}

The DE of pectin was measured on the basis methoxyl and AUA content [24] and calculated by flowing formula.

$$
\% D E=\frac{175 \times \% M e O}{31 \times \% A U A} \times 100
$$

\subsection{Regression models}

The regression models of the responses (yields, EW, MeO, AUA content, and DE) were calculated by the mean of the MPV design provided by the Minitab ${ }^{\circledR}$ 18.1 Software (Minitab Inc., State College, PA, USA). Equation 9 gives the regression model which results from the crossing (Equation 8) of the Scheffé's quadratic model for components in Equation 6, and the full factorial model for the process variables in Equation 7. The full model contains 24 terms $[12,14]$.

$$
\begin{gathered}
f(x)=\beta_{1} x_{1}+\beta_{2} x_{2}+\beta_{3} x_{3}+\beta_{12} x_{1} x_{2}+\beta_{13} x_{1} x_{3}+\beta_{23} x_{2} x_{3} \\
g(z)=\alpha_{0}+\alpha_{1} z_{1}+\alpha_{2} z_{2}+\alpha_{12} z_{1} z_{2} \\
R_{x, z}=f(x) \times g(z) \\
R_{x, z}=\gamma_{1}^{0} x_{1}+\gamma_{2}^{0} x_{2}+\gamma_{3}^{0} x_{3}+\gamma_{12}^{0} x_{1} x_{2}+\gamma_{13}^{0} x_{1} x_{3}+\gamma_{23}^{0} x_{2} x_{3}+ \\
\gamma_{1}^{1} x_{1} z_{1}+\gamma_{2}^{1} x_{2} z_{1}+\gamma_{3}^{1} x_{3} z_{1}+\gamma_{1}^{2} x_{1} z_{2}+\gamma_{2}^{2} x_{2} z_{2}+\gamma_{3}^{2} x_{3} z_{2}+ \\
\gamma_{12}^{1} x_{1} x_{2} z_{1}+\gamma_{13}^{1} x_{1} x_{3} z_{1}+\gamma_{23}^{1} x_{2} x_{3} z_{1}+\gamma_{12}^{2} x_{1} x_{2} z_{2}+ \\
\gamma_{13}^{2} x_{1} x_{3} z_{2}+\gamma_{23}^{2} x_{2} x_{3} z_{2}+\gamma_{1}^{12} x_{1} z_{1} z_{2}+\gamma_{2}^{12} x_{2} z_{1} z_{2}+ \\
\gamma_{3}^{12} x_{3} z_{1} z_{2}+\gamma_{12}^{12} x_{1} x_{2} z_{1} z_{2}+\gamma_{13}^{12} x_{1} x_{3} z_{1} z_{2}+\gamma_{23}^{12} x_{2} x_{3} z_{1} z_{2}
\end{gathered}
$$

$R_{x, y}$ represents the overall values of the responses. $x_{i}$ 's are the linear terms of components, $x_{i} x_{j}$ 's are the quadratic terms of components. $x_{i} z_{l}$ 's are the interaction terms of the individual sources with the $\mathrm{pH}$ or the LSR. $x_{i} x_{j} z_{l}$ 's are the interaction terms of the mixes with the $\mathrm{pH}$ or the LSR. $x_{i} z_{l} z_{m}$ 's are the interaction terms of the individual sources with the $\mathrm{pH}$ and the LSR, and $x_{i} x_{j} z_{l} z_{m}$ 's are the interaction terms of the mixes with the $\mathrm{pH}$ and the LSR. The $\gamma^{\prime}$ s are the coefficients of the model. The lower indexes of $\gamma$ refer to the components, whereas the upper ones refer to process variables.

\subsection{Data processing}

Data were treated using the Minitab ${ }^{\circledR}$ 18.1 Software (Minitab Inc., State College, PA, USA). The model accuracy was tested by $\mathrm{R}^{2}$, adjusted $\mathrm{R}^{2}$, predicted $\mathrm{R}^{2}$ and value of $\mathrm{S}$ or the "standard error of the model" [24]. A lower value of $S$ indicates a better fitting models. The values of $S, R^{2}$ and adjusted $R^{2}$ indicate how well the models fit the observed data. The value of predicted $\mathrm{R}^{2}$ is indicator of how well the regression models predict new observations [25]. The regression models were validated by the ANOVA of the regression terms ( $\mathrm{p}$-value $<0.05$ ).

The effect of the mixing and the process variables on the quality of the pectins were evaluated by the mean of the mixture contour plots of the $\mathrm{EW}$, the $\mathrm{MeO}$, the AUA contents and the DE.

The preponderant regions corresponding to the optimum yields and the optimum qualities of pectins were scanned with the overlaid contour plot provided by the Minitab Software. It identifies regions on a contour plot where the fitted models predict acceptable results for both the quantitative and the qualitative responses. The optimal points at these regions were identified by the mean of the response optimizer tool accessible in the Minitab Software. It identifies the combination of predictor settings that jointly optimize the fitted responses.

The field of the reasearch was divided into 4 parts according to the value of the DE: between 0 and 50 for LMP, between 58 and 
65 for slow set HMP, between 66 and 69 for medium set HMP, and between 71 and 74 for rapid set HMP [26]. The limits of the other responses were fixed with agreement to the standard specifications and according to their minimum or maximum limits. Theses limits were: between $6 \%$ and $48 \%$ for the extraction yields, between 600 [27] and 1158 for the EW, between 0.5 and 7 for the $\mathrm{MeO}$ of LM-pectins, between 7 and 12 for the MeO of HMpectins, and between $65 \%$ [28] and $88 \%$ for AUA content.

\section{RESULTS}

\subsection{Quantitative and qualitative responses}

The averages of the quantitative (yield) and the qualitative responses (EW, AUA content, $\mathrm{DE}$, and $\mathrm{MeO}$ ) from the 28 experiments with 2 replicates are given in table 3 .

\subsection{Validity of the models}

Table 4 shows the Model coefficients of the extraction yield, the EW, the AUA content, the $\mathrm{MeO}$, and the DE. The high F-values $(3297.59,2309.13,239.37,335.11$, and 576.39 respectively) and the p-values $(<0.0001)$ demonstrated the validity of the models. The coefficients between brackets are not significant according to the ANOVA tests. The values of $\mathrm{S}(0.32,5.6,0.9,0.18,0.84$ respectively), the values of $\mathrm{R}^{2}(0.9996,0.9994,0.9942,09959$, and 0.9976 respectively) and the values of adjusted $\mathrm{R}^{2}(0.9993$, $0.9990,09901,0.9929$, and 0.9959 respectively) of the responses indicate that the models fit the observed data. The values of the predicted $\mathrm{R}^{2}$ (0.9987, 0.9980, 0.9789, 09.845, and 0.9911 respectively) and the irrelevant p-values of lack of fit performance $(0.737,0.104,0.112,0.548$, and 0.371 respectively) indicate that the predicted values could reasonably represent the experimental values of all the responses [25, 29]. The predicted models of the yields, EW, AUA contents, MeO, and DE could be utilized to the optimization of the responses at the experimental domain.

\subsection{Characterization of the assessed pectins}

The EW, AUA content, $\mathrm{MeO}$ and $\mathrm{DE}$ of pectins from individual sources and from the mixtures in table 3 were analyzed to characterize them. The effect of the mixing and the process variables ( $\mathrm{pH}$ and LSR) were appreciated by the mean of the mixture contour plot. The linear and quadratic terms in table 4 were utilized to explain the contour plots.

\subsubsection{Mixture contour plot of the EW}

The EW of the samples ranged from 350 to 1054 . The linear terms of EWs (Table 4) of mango and passion fruits (527.66 and 508.44 respectively) were under the standard specification (> 600) [27]. It was not the case of Bambara groundnut (797.34). Low pH tend to decrease the EWs. At pH 1.5, the EWs of mango and passion fruits-rich mixtures were all under 400 but the EWs of Bambara groudnut rich mixtures remained up to 600. The values of EWs at $\mathrm{pH} 2$ were all superior to 600. The EWs of Bambara grounut-rich mixture reach up to 900 at this condition. The high LSR improved slighty the EWs except for Bambara groundnut (figure 2).

\subsubsection{Mixture contour plot of the AUA contents}

The means of AUA contents (Table 4) of mango and passion fruits $(82.30 \%$ and $82.23 \%$ respectively) fit the standard specification
$(>65 \%)$. The case of Bambara groundnut was different $(63.55 \%)$. Nevertheless, its AUA contents could meet this standard at high $\mathrm{pH}$. The AUA contents of the individual sources and the mixes increased with the augmentation of $\mathrm{pH}$ from 1.5 to 2 .

Tableau 3: Experiment results

\begin{tabular}{|r|c|c|c|c|c|c|c|c|}
\cline { 2 - 10 } \multicolumn{1}{c|}{} & \multicolumn{2}{|c|}{ MPV design } & \multicolumn{5}{c|}{ Responses } \\
\hline Run & Mix & pH & LSR & Yield & EW & AUA & MeO & DE \\
\hline 1 & M & 1.5 & 15 & 42.9 & 368.9 & 82.2 & 6.1 & 42.0 \\
\hline 2 & P & 1.5 & 15 & 34.2 & 392.3 & 85.3 & 7.1 & 47.4 \\
\hline 3 & B & 1.5 & 15 & 23.9 & 694.4 & 47.0 & 3.8 & 46.1 \\
\hline 4 & MP & 1.5 & 15 & 40.8 & 387.8 & 77.5 & 5.6 & 41.4 \\
\hline 5 & MB & 1.5 & 15 & 45.5 & 540.8 & 66.2 & 5.9 & 50.8 \\
\hline 6 & PB & 1.5 & 15 & 31.4 & 502.8 & 69.0 & 6.0 & 49.2 \\
\hline 7 & MPB & 1.5 & 15 & 41.1 & 473.5 & 69.4 & 5.7 & 46.3 \\
\hline 8 & M & 1.5 & 12.5 & 43.8 & 352.0 & 84.0 & 4.7 & 31.4 \\
\hline 9 & P & 1.5 & 12.5 & 24.4 & 386.4 & 82.0 & 6.4 & 44.3 \\
\hline 10 & B & 1.5 & 12.5 & 24.1 & 591.0 & 62.8 & 5.4 & 48.7 \\
\hline 11 & MP & 1.5 & 12.5 & 31.3 & 336.0 & 84.0 & 5.4 & 36.5 \\
\hline 12 & MB & 1.5 & 12.5 & 39.1 & 447.2 & 74.1 & 6.1 & 46.6 \\
\hline 13 & PB & 1.5 & 12.5 & 21.6 & 428.4 & 73.5 & 5.7 & 43.8 \\
\hline 14 & MPB & 1.5 & 12.5 & 30.9 & 386.4 & 78.4 & 5.8 & 42.1 \\
\hline 15 & M & 2 & 15 & 29.2 & 743.5 & 76.4 & 9.3 & 69.0 \\
\hline 16 & P & 2 & 15 & 25.1 & 631.7 & 85.9 & 10.2 & 67.6 \\
\hline 17 & B & 2 & 15 & 13.8 & 861.3 & 75.0 & 9.6 & 72.7 \\
\hline 18 & MP & 2 & 15 & 28.0 & 624.2 & 84.5 & 9.9 & 66.6 \\
\hline 19 & MB & 2 & 15 & 18.4 & 608.6 & 82.4 & 9.4 & 64.9 \\
\hline 20 & PB & 2 & 15 & 21.6 & 768.6 & 63.4 & 7.1 & 63.9 \\
\hline 21 & MPB & 2 & 15 & 22.5 & 628.1 & 77.3 & 8.7 & 63.7 \\
\hline 22 & M & 2 & 12.5 & 10.4 & 645.2 & 86.6 & 10.4 & 68.5 \\
\hline 25 & P & 2 & 12.5 & 9.6 & 622.3 & 75.7 & 8.3 & 62.6 \\
\hline 24 & B & 2 & 12.5 & 5.8 & 1041.5 & 69.4 & 9.5 & 77.8 \\
\hline 25 & MP & 2 & 12.5 & 12.8 & 588.2 & 78.8 & 8.6 & 62.1 \\
\hline 26 & MB & 2 & 12.5 & 11.5 & 836.1 & 84.2 & 11.1 & 75.0 \\
\hline 27 & PB & 2 & 12.5 & 9.0 & 693.7 & 85.2 & 10.5 & 70.0 \\
\hline 28 & MPB & 2 & 12.5 & 12.1 & 687.0 & 83.8 & 10.2 & 69.4 \\
\hline
\end{tabular}

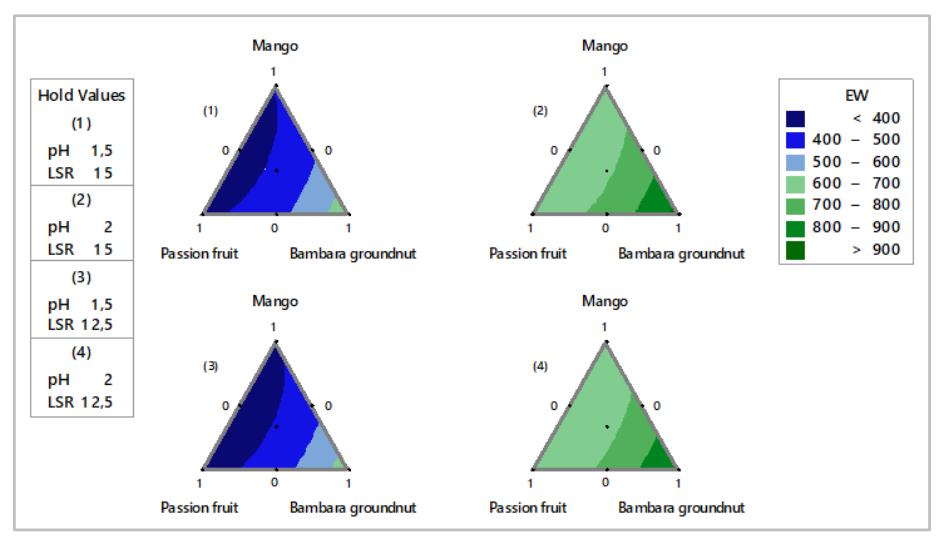

Figure 2: Multiple mixture contour plot for EW

Low LSR also affected positively the AUA contents. High $\mathrm{pH}$ and low LSR medium was the best condition to conserve the maximum of the AUA contents (figure 3 ). 


\subsubsection{Mixture contour plot of the $\mathrm{MeO}$}

The $\mathrm{MeO}$ contents can be clasified into two categories: between $0.5 \%$ and $7 \%$ for LMP, and between $7 \%$ and $12 \%$ for HMP [26]. Extraction at $\mathrm{pH} 1.5$ gave a value of $\mathrm{MeO}$ under $7 \%$. But the values of the $\mathrm{MeO}$ at $\mathrm{pH} 2$ ranged between $9 \%$ and $11 \%$ (figure 4).

\subsubsection{Mixture contour plot of the $D E$}

When the $\mathrm{pH}$ was set at 1.5 , the DEs were under $50 \%$ except for Bambara groundnut which DEs ranged between 50 and 55\%. At $\mathrm{pH} 2$, the DEs were above 50\% and can reached up to $70 \%$ for Bambara groundnut. High LSR increased the DEs of mango and/or passion fruit-rich mixtures but it decreased the DEs of Bambara groundnut-rich pectins (figure 5).

Table 4: Model coefficients of the responses

\begin{tabular}{|c|c|c|c|c|c|c|}
\hline & Terms & Yield & EW & AUA & $\mathrm{MeO}$ & $\mathrm{DE}$ \\
\hline \multirow{3}{*}{$\begin{array}{l}\text { Linear } \\
\text { terms }\end{array}$} & M & 31,569 & 527.66 & 82.30 & 7.62 & 52.75 \\
\hline & $\mathrm{P}$ & 23,313 & 508.44 & 82.23 & 8.03 & 55.51 \\
\hline & $\mathrm{B}$ & 16,863 & 797.34 & 63.55 & 7.08 & 61.36 \\
\hline \multirow{3}{*}{$\begin{array}{l}\text { Quadratic } \\
\text { terms }\end{array}$} & MP & 3,273 & -140.38 & -4.25 & -1.76 & -10.28 \\
\hline & MB & 17,687 & -221.52 & 15.21 & 3.10 & 8.73 \\
\hline & $\mathrm{PB}$ & 3,285 & -222.42 & $(-0.46)$ & -0.97 & -7.10 \\
\hline \multirow{6}{*}{$\begin{array}{l}\text { Interaction } \\
\text { terms with } \\
\mathrm{pH}\end{array}$} & $\mathrm{M}^{*} \mathrm{pH}$ & $-11,783$ & 167.05 & -0.80 & 2.25 & 15.98 \\
\hline & $\mathrm{P} * \mathrm{pH}$ & $-5,966$ & 118.93 & -1.46 & 1.25 & 9.56 \\
\hline & $\mathrm{B} * \mathrm{pH}$ & $-7,1$ & 154.44 & 8.62 & 2.47 & 13.89 \\
\hline & $\mathrm{M} * \mathrm{LSR}$ & 4,464 & 29.00 & -2.97 & $(0.07)$ & 2.79 \\
\hline & P*LSR & 6,328 & 4.05 & 3.38 & 0.65 & 2.04 \\
\hline & $\mathrm{B} * \mathrm{LSR}$ & 1,955 & -18.98 & -2.57 & -0.37 & -1.91 \\
\hline \multirow{6}{*}{$\begin{array}{l}\text { Interaction } \\
\text { terms with } \\
\text { LSR }\end{array}$} & MP*pH & 4,154 & -84.72 & 6.70 & (0.59) & $(0.45)$ \\
\hline & $\mathrm{MB} * \mathrm{pH}$ & $-16,994$ & -187.77 & 10.91 & -0.81 & -16.49 \\
\hline & $\mathrm{PB}^{*} \mathrm{pH}$ & 3,696 & $(-17.00)$ & -8.04 & -1.38 & -5.32 \\
\hline & MP*LSR & 3.046 & 18.49 & $(-1.68)$ & $(0.10)$ & $(-0.57)$ \\
\hline & MB*LSR & $(0.295)$ & -157.10 & (1.30) & -1.28 & -8.02 \\
\hline & PB*LSR & 5.658 & 176.01 & -28.04 & -3.65 & -1.41 \\
\hline \multirow{6}{*}{$\begin{array}{l}\text { Interaction } \\
\text { terms with } \\
\mathrm{pH} \text { and } \\
\text { LSR }\end{array}$} & $\mathrm{M} * \mathrm{pH}^{*} \mathrm{LSR}$ & 4.916 & 20.68 & -2.18 & -0.65 & -2.51 \\
\hline & $\mathrm{P}^{*} \mathrm{pH} \mathrm{H}^{*} \mathrm{LSR}$ & 1.396 & (1.18) & 1.65 & 0.28 & $(0.44)$ \\
\hline & $\mathrm{B} * \mathrm{pH} \mathrm{H}^{*} \mathrm{LSR}$ & 2.057 & -70.59 & 5.28 & 0.41 & $(-0.61)$ \\
\hline & MP*pH*LSR & -6.966 & -64.55 & 14.38 & 1.92 & 3.97 \\
\hline & $\mathrm{MB}^{*} \mathrm{pH}^{*} \mathrm{LSR}$ & -13.554 & -226.30 & (1.04) & -0.94 & -7.97 \\
\hline & PB*pH*LSR & -4.144 & 134.29 & -29.94 & -4.94 & -11.11 \\
\hline \multicolumn{2}{|l|}{$\mathrm{R}^{2}$} & 0,9996 & 0.9994 & 0.9942 & 0.9959 & 0.9976 \\
\hline \multicolumn{2}{|l|}{$\mathrm{R}^{2}$-adjusted } & 0,9993 & 0.9990 & 0.9901 & 0.9929 & 0.9959 \\
\hline \multicolumn{2}{|c|}{$\mathrm{R}^{2}$-predicted } & 0,9987 & 0.9980 & 0.9798 & 0.9845 & 0.9911 \\
\hline \multicolumn{2}{|c|}{ F-value of the model } & 3297.59 & 2309.13 & 239.37 & 335.11 & 576.39 \\
\hline \multicolumn{2}{|c|}{ p-value of the model } & $<0,0001$ & $<0,0001$ & $<0,0001$ & $<0,0001$ & $<0,0001$ \\
\hline \multicolumn{2}{|l|}{ Lack of fit } & 0.737 & 0.104 & 0.112 & 0.548 & 0.371 \\
\hline \multicolumn{2}{|l|}{$S$} & 0,32 & 5,6 & 0,9 & 0,18 & 0,84 \\
\hline
\end{tabular}

\subsection{Optimization}

The preponderant regions of optimum yields of marketable LMP and HMP were first scanned using Minitab ${ }^{\circledR}$ 18.1 Software (Minitab Inc, State College, PA, USA) by varying the $\mathrm{pH}$ and the LSR between their low and their high levels. The seeking of the preponderant regions allowed to go more quickly with the optimization. Then, the yield, the EW, and the AUA content were optimized at once. The $\mathrm{DE}$ and the $\mathrm{MeO}$ served for the classification of the pectins as LMP and HMP (slow set. medium set. and rapid set).

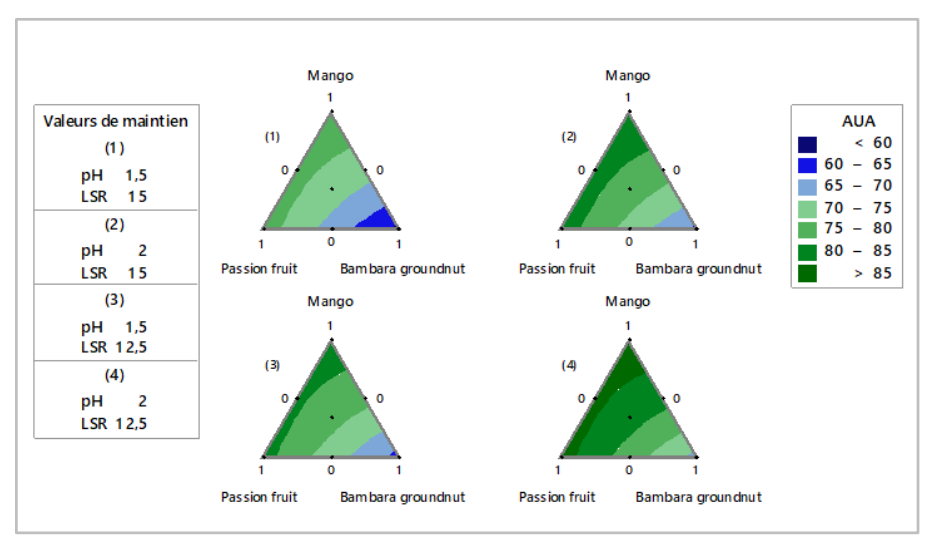

Figure 3: Multiple mixture contour plot of AUA contents

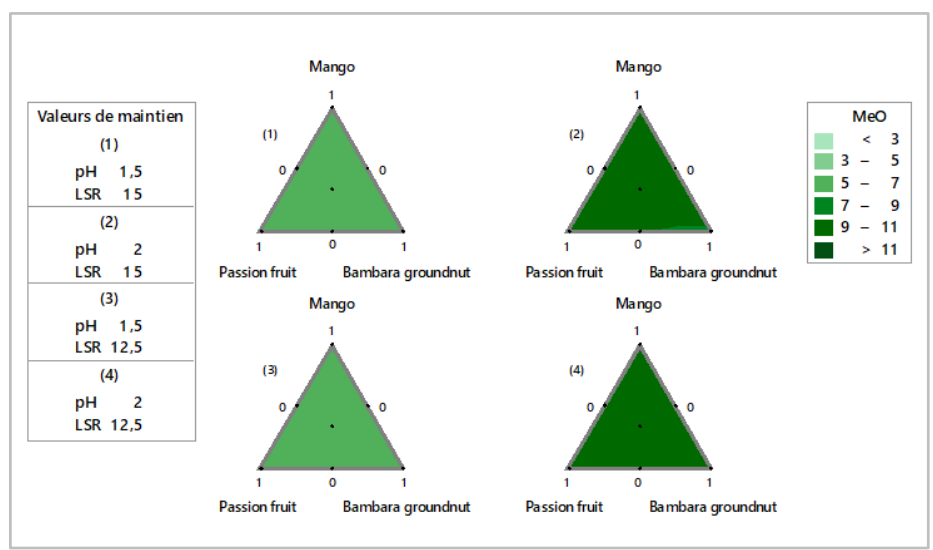

Figure 4: Multiple mixture contour plot of the $\mathrm{MeO}$

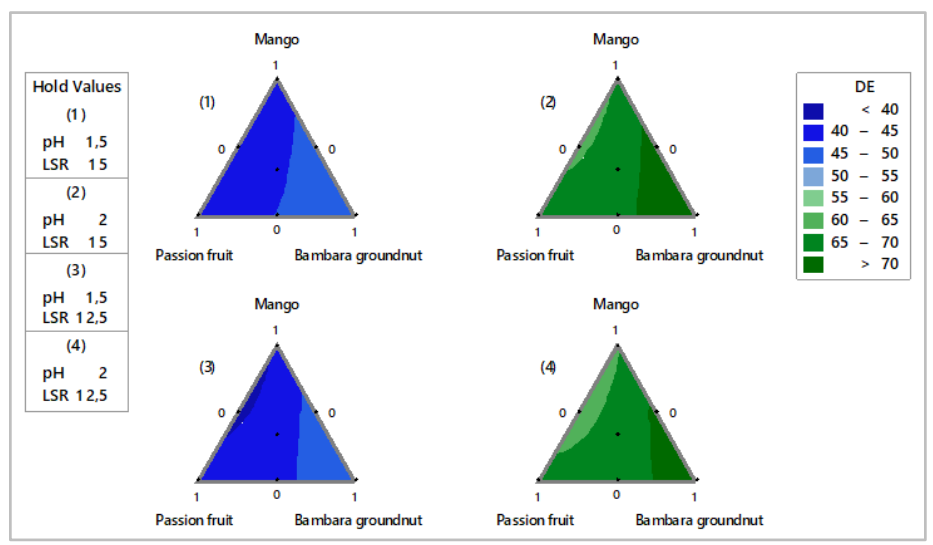

Figure 5: Multiple mixture contour plot of the DE

\subsubsection{Preponderant region for $L M P$}

The preponderant region for LMP in the mixture design was predicted by Minitab ${ }^{\circledR}$ 18.1 Software using the responses' models (table 4). The software utilized the predicted model of each response and drew their contour plots in the mixture design. The white-colored area in figure 6 corresponds to the preponderant 
region of LMP. Production of marketable LMP is possible at the region of MB mix where Bambara groundnut is present at high proportion.
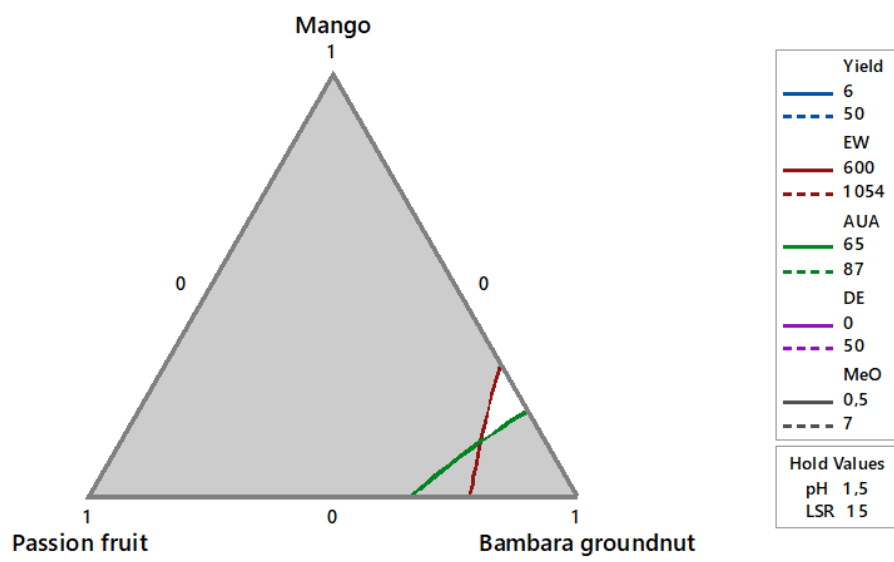

Figure 6: Preponderant region for LMP

\subsubsection{Preponderant region for $H M P$}

Five preponderant regions for the HMP (white area) were scanned at the mixture design by varying the $\mathrm{pH}$ and the LSR and by defining the suitable limits of the important parameters as yield, $\mathrm{EW}, \mathrm{MeO}, \mathrm{AUA}$ contents and DE. The group of three regions, observable at $\mathrm{pH} 1.75$, belongs to the area of the mixes with high proportion of Bambara groundnut. The second group of preponderant regions is detected at $\mathrm{pH} 2$. It widened with the growth of the LSR, extending from the area of MP mix until the area of MB mix (Figure 7).

\subsection{3. classification of the optimized pectins}

The three responses (yield, EW, AUA contents) were optimized together by fixing the suitable values of the $\mathrm{DE}$ and the $\mathrm{MeO}$ corresponding to the category of the desired pectin.

Table 5 shows the optimized pectins in term of yields, EW and AUA contents. They were also classified into four categories according to the values of the $\mathrm{MeO}$ and the DEs. The optimal conditions of the procurement of LMP is at $\mathrm{pH} 1.5$ and LSR $15 \mathrm{ml} / \mathrm{g}$. The optimal yield reached up to $40.6 \%$. This category of pectin derived from MB mix where the proportion of mango is $31.3 \%$, the percentage of Bambara groundnut attains $68.7 \%$. Its EW (600.2) and AUA content (67.9\%) fit the standard specification.

Three categories of optimized HMP can be scanned from the preponderant regions. Good yield of slow set pectin (32.0\%) will be available at $\mathrm{pH} 1.77$ and LSR $15 \mathrm{ml} / \mathrm{g}$ from the proportion of $56.6 \%$ of mango peel and $43.4 \%$ of Bambara groundnut shell. The EW and the AUA content of this pectin are respectively equal to 606.4 and $75.9 \%$. An optimum yield of $27.5 \%$ of medium set pectin will be assessed at $\mathrm{pH} 2$ and LSR $14.96 \mathrm{ml} / \mathrm{g}$ with the mix composed by $95 \%$ of mango and $5 \%$ of Bambara groundnut. The EW reaches up to 669 , the AUA content is excellent (82.3\%). Finally, 19\% of rapid set pectin will be extracted from the mix composed by $54.6 \%$ of mango and $45.4 \%$ of Bambara groundnut at $\mathrm{pH} 2$ and LSR $15 \mathrm{ml} / \mathrm{g}$. The EW is better than the previous types (733.8), the AUA content is equal to $78 \%$.
Table 5: Optimization and classification of pectins

\begin{tabular}{|l|c|c|c|c|c|c|c|c|}
\hline $\begin{array}{l}\text { Type of } \\
\text { pectin }\end{array}$ & $\begin{array}{c}\text { Proportion } \\
\text { MB }(\%)\end{array}$ & $\mathrm{pH}$ & LSR & $\begin{array}{c}\text { Yield } \\
(\%)\end{array}$ & EW & $\begin{array}{c}\text { AUA } \\
(\%)\end{array}$ & MeO & DE \\
\hline LMP & $31.3 / 68.7$ & 1.5 & 15 & 40.3 & 600.2 & 67.9 & 5.88 & 49.0 \\
\hline Slow set & $56.6 / 43.4$ & 1.77 & 15 & 32.0 & 606.4 & 75.9 & 8.15 & 59.9 \\
\hline Medium set & $95.0 / 5.0$ & 2 & 14.96 & 27.5 & 669.0 & 82.6 & 9.52 & 66.1 \\
\hline Rapid set & $54.6 / 45.4$ & 2 & 15 & 19.0 & 733.8 & 78.0 & 9.92 & 71.3 \\
\hline
\end{tabular}
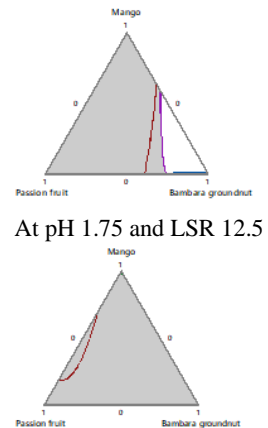

At $\mathrm{pH} 2$ and LSR 12.5

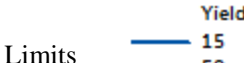

Limits
At pH 1.75 and LSR 12.5

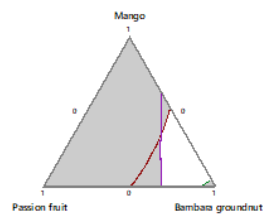

At pH 1.75 and LSR 13.75

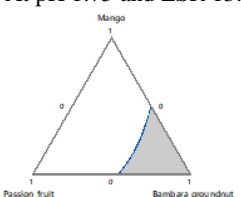

parcont neer

At $\mathrm{pH} 2$

ISR 13.7

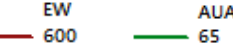

$-1054 \quad 65$
-----87

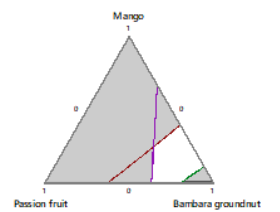

At pH 1.75 and LSR 15

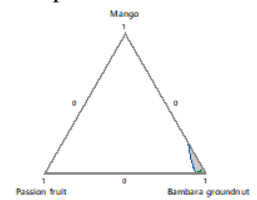

At pH 2 and LSR 15

$\begin{array}{cr}\text { MeO } & \text { DE } \\ 7 & 58 \\ ---12 & ---77\end{array}$
Figure 7: Preponderant regions for HMP

\section{Discussions}

\subsection{Characterization}

\subsubsection{Equivalent weight (EW)}

The EW is the amount in grams of pure polygalacturonic acid. It depends on the degree of esterification, which is correlated with the number of free carboxylic groups in one gram mole equivalent to one gram mole of hydroxy [21]. The EW of pectin samples indicates its jelly-forming ability, wherein better gelling agents possess higher equivalent weight [30].The EW of all mixtures ranged from 350 to 1054, it was somewhat under the EW of lemon pomace pectin comprised from 368-1632, publised by Azad et al. (2014) [31]. Nahar et al. (2017) [32] found that EW of mango peel cultivars varied from 506.58-2142 depending on the extraction condition used. They found a value of $654.14 \pm 0.67$ using citric acid at $\mathrm{pH} 1.5$ and LSR $20 \mathrm{ml} / \mathrm{g}$. At the same $\mathrm{pH}$ and at LSR $15 \mathrm{ml} / \mathrm{g}$, the EWs of mango, passion fruit and bambara groundnut were respectively: $368.87,390.6$ or 392.32 and 694.44. This comparison confirms that high LSR improves the EW of mango.

The values of the EW of pectins using citric acid were often under those extracted by other types of acid. Uzma et al. (2015) [33], stipulated that EW of papaya peel pectin extracted using $\mathrm{HCl}$ and citric acid was 912.17 and 455.1 respectively. Devi et al. (2014) [34], demonstrated that the EW of pectin extracted from sweet lemon peel powder using citric and nitric was found to be 312.5 and 833.33 respectively.

The standard of EW published by International Pectin Producers Association (IPPA) in 2002 [27] ranges from 600-800 mg. At pH 1.5 , most of the EW of components were inferior to this standard except for Bambara groundnut. For individual sources, the EWs 
were decreased significantly with the lessening of the $\mathrm{pH}$. Nazaruddin (2011) [35] also argued that the decreasing of the EW depends upon the amount of free acid. However, mixing with bambara groundnut improves the EW of the samples even at low $\mathrm{pH}$. This is the reason why the optimized LMP meets the standard specification with the mix composed by $31.3 \%$ of mango and $68.7 \%$ of Bambara groundnut (table 5 ).

\subsubsection{Anhydrouronic acid content (AUA)}

The AUA content indicates the purity of pectin. The value of AUA content should not be less than $65 \%[27,36]$. AUA content of less than $65 \%$ may indicate impurities due to the presence of proteins, starch, ash, and sugars in the precipitated pectin [37]. So, pectins from mango and passion fruit (average of AUA contents $82.3 \%$ and $82.2 \%$ respectively) are purer than pectin from Bambara groundnut (mean of AUA contents $63.5 \%$ ). The low purity of Bambara groundnut shell pectin may be proven by its high ash and its high protein contents. To confirm this, Mahala and Mohammed (2010) [38] published the chemical composition of Bambara groundnut shell containing $15.306 \%$ of crude protein, $25.193 \%$ of crude fiber, $3.523 \%$ of fat and $3.845 \%$ of ash. The overall yield of Bambara shell pectin found in this research $(16,863 \%)$ is in accordance with this percentage of crude fiber.

The best condition to the procurement of good amount of AUA was at $\mathrm{pH} 2$ and LSR $12.5 \mathrm{ml} / \mathrm{g}$ for all samples. Thomas et al. (2008) affirmed that lower $\mathrm{pH}$ values negatively affected the galacturonic acid content of pectin, but increased the pectin yield. It seems that, for some species like Bambara groundnut, the low $\mathrm{pH}$ induces the mobilization of the other components (divalent cations, starch, and proteins) that contaminates the pectin. Several authors published low AUA content at $\mathrm{pH}$ 1.5: (i) 57.32\% for ripe banana peel and $39.68 \%$ for unripe banana peel using $\mathrm{HCl}$ [39], (ii) $65.4 \%$ for lemon peel using nitric acid [40], (iii) $63.2 \%$ with honeydew (Cucumis melo l. var. inodorous) using citric acid [41].

The increasing of the LSR lessened the amount of AUA. The water activity would provoke the mobilization of protein and polyphenols [42] which reduce the purity of the pectins. Mixing with Bambara groundnut decreased the purity of the mix. However, the purity of the three categories of the optimized Bambara groundnut mixes found in this research satisfies the standard specification: $75.9 \%$ for slow set MB mix pectin, $82.6 \%$ for medium set $\mathrm{MB}$ mix pectin, and $78.0 \%$ for rapid set MB mix pectin (table 5).

\subsubsection{Methoxyl content ( $\mathrm{MeO})$}

The $\mathrm{MeO}$ content is an important factor in controlling the setting time of pectins and the ability of pectin to form gels [43]. Pectin's spreading quality and sugar binding capacity were increased with increasing $\mathrm{MeO}$ content [44]. The methoxyl content also is an important variable that determines the sensitivity of its response to polyvalent cations. If the methoxyl content is high, it indicates that the pectin will gel quickly. Regular pectins have a methoxyl content between $7 \%$ and $12 \%$ and are also called high-methoxyl pectins (HMP). Pectins with a methoxyl content between $0.5 \%$ and $7 \%$ are known as low-methoxyl pectins (LMP). LMP are used in the manufacture of dietetic and lower-calorie fruit jellies [26].

This publication is licensed under Creative Commons Attribution CC BY.

http://dx.doi.org/10.29322/IJSRP.11.08.2021.p11616
At $\mathrm{pH} 1.5$, the $\mathrm{MeO}$ of all the components was under $7 \%$. That is the reason of the possibility of obtaining LMP from mixtures at this condition. At $\mathrm{pH} 2$, the values of the $\mathrm{MeO}$ were superior to $7 \%$. At this condition, all the components are able to form gels in presence of sugar. This is the reason why three types of HMP are available at this condition.

\subsubsection{Degrees of Esterification (DE)}

$\mathrm{DE}$ is the identification parameter for classifying of pectins. DE > $50 \%$ are known as HMP and a DE < 50\% are LMP [45]. HMP forms gels under acidic conditions $(\mathrm{pH}<4.0)$ with sucrose (> $55 \%$ ) [46], whereas LMP forms gels by the interaction of divalent cations, especially $\mathrm{Ca}^{2+}$, between free carboxyl groups [47]. However, the DE represents only the ratio between methanolesterified carboxyl groups and free carboxyl groups, whereas the $\mathrm{MeO}$ refers to the amount of methoxyl groups in a sample [48]. Therefore, the DE should not be assessed separately, as it does not represent the actual amount of methyl esterification, especially when the AUA content is low.

The DE of mango in this study ranged from 31.4 to $69.1 \%$ (table 3). Nahar et al. (2017) [34] found a value from 40.99 to $79.16 \%$ for Mango cultivars. Passion fruit in the present study had a DE ranging from 41.3 to $67.6 \%$. Liew et al., 2014 [49] argued a value from 41.67 to $67.31 \%$ using citric acid at $\mathrm{pH}$ ranging from 2 to 4.5 and at LSR of $25 \mathrm{ml} / \mathrm{g}$. Pinheiro et al. (2008) [50] also reported the recovery of HMP from yellow passion fruit peels using citric acid. Kliemann et al. (2009) [53] have successfully recuperated LMP from yellow passion fruit wastes through acid extractions. DE of Bambara groundnut varied from 45.5 to $78.0 \%$. These values were higher than of mango and passion fruit. These results demonstrated the possibility of obtaining of both HMP and LMP from the three individual sources.

Generally, the DEs of the individual sources increased when the $\mathrm{pH}$ and the LSR augmented except for Bambara groundnut where DE decreased with the LSR. According to Kliemann et al. (2009) [51], higher LSR of citric acid increased pectin DE. This finding is confirmed with mango and passion fruit pectins but is not in the case of Bambara groundnut pectin. Like the AUA content, the DEs of Bambara groundnut and its mixtures decreased when the LSR raised up.

The pectins obtained at low acidic condition ( $\mathrm{pH} 1.5)$ can be considered as LMP because they had a DE inferior to 50\% except for Bambara groundnut $(<55 \%)$. At $\mathrm{pH} 2$, all the pectins had a DE superior to $50 \%$ and can be classified as HMP. DE increased with increasing $\mathrm{pH}$. The result was relevant to the previous study [32, 52]. The access of different values of $\mathrm{DE}$ at the two acidic condition $(<55 \%$ at $\mathrm{pH} 1.5$ and $>55 \%$ at $\mathrm{pH} 2)$ and the antagonism between mango/passion fruit and Bambara groundnut in the two condition of LSR offer the possibility of the production of interesting pectin in term of yield and in term of quality.

\subsection{Optimization}

\subsubsection{Low Methoxyl pectin (LMP)}

The results confirm the role of Bambara groundnut in the mixture as mentioned above. None of the plant sources match to the specifications because of the EW content $(\geq 600)$. Bambara 
groundnut alone offers high level of $\mathrm{EW}$ at severe extraction conditions. Mixing leads to an improvement of the yield due to the antagonism between mango/passion fruit and Bambara groundnut during extraction. The optimum yield (40.3\%) from mangoBambara mix is higher than the published yields from conventional sources [10]. The co-existence of the two sources in the extractor permits the creation of a local condition that is favorable simultaneously in the improvement of the extraction yield [12] and in the preservation of the quality of the weak pectin against severe extraction conditions. Then, mixing is an appropriate method to the production of LMP in low acidic condition when the two plant sources present different comportment during extraction.

\subsubsection{High Methoxyl pectins (HMP)}

It was possible to obtain high yields and good qualities of different types of HMP thanks to the presence of Bambara groundnut in the mixes. Good qualities of slow set pectin (30.0\%), medium set pectin $(27.5 \%)$, and rapid set pectin $(19.0 \%)$ were obtained from the MB mix. These results demonstrates again the advantage of mixing two plant sources when they have different comportment at the experimental conditions. MP mix was not excellent compared to the mango alone and the passion fruit alone because they had similar comportment during extraction. The yields above can compete those of the commercial pectins comprised between $15-30 \%$ (for citrus peel) and 10-15\% (for apple pomace) on a dry weight basis [10].

\section{Conclusion}

The EW, MeO, AUA contents and DE are important parameters to characterize pectins. The EW evaluates the weigth of pure galacturocic acid wich is correlated to the ability of pectin to form gel. The $\mathrm{MeO}$ and the DE are importants factors in controlliig setting time of pectins. They are utilised for the classification of pectin in two groups: LMP and HMP. The DE also allows to categorize the HMP in four types: slow set, medium set, rapid set and ultra-rapid set. The AUA content indicates the purity of pectins. It should not be less than $65 \%$.

The extraction yield of pectins and the values of the previous experimental responses depended on the plant source, the mixing ratio, the $\mathrm{pH}$ and the LSR. Mango and passion fruit pectins had high extraction yields and high AUA contents. But they had feeble value of $\mathrm{EW}, \mathrm{MeO}$ and $\mathrm{DE}$ especially in more acidic extraction. In the contrary, Bambara groundnut pectin showed moderate AUA content and showed appreciable values of $\mathrm{EW}, \mathrm{MeO}$ and $\mathrm{DE}$ at low $\mathrm{pH}$. As the $\mathrm{MeO}$ and the $\mathrm{DE}$ are influenced by the $\mathrm{pH}$, the variation of $\mathrm{pH}$ offers the possibility of the production of both LMP and HMP. The antagonism comportment of mango/passion fruit and Bambara groundnut in different level of $\mathrm{pH}$ and LSR is profitable for the obtaining of high yielded-pectins of good quality. They can be achieved by varying the proportion of mixture, the $\mathrm{pH}$ and the LSR. This is possible due to utilization of MPV design which can be considered as an innovative and efficient method in the domain of pectin extraction.

Four classes of optimized pectins were found in this research: $40.26 \%$ of LMP derived from $31.31 \%$ of mango and $68.69 \%$ of Bambara groundnut, $32.00 \%$ of slow set pectin resulting from the mix of $56.6 \%$ of mango and $43.4 \%$ Bambara groundnut, $27.5 \%$ of medium set pectin obtained from $95.0 \%$ mango and $5.0 \%$ of Bambara groundnut, $19.0 \%$ of rapid set pectin available from $54.6 \%$ of mango and $45.4 \%$ of Bambara groundnut.

\section{ACKNOWLEDGMENTS}

The author thank especially the College of Agricultural Sciences and the Doctoral School for Engineering of Processes and Industrial, Agricultural and Food Systems at the University of Antananarivo, and the Plant-Health Laboratory. This work could not be carried out without their supports.

\section{REFERENCES}

[1] S. Levigne, M.C. Ralet and J.F.Thibault. Characterization of pectins extracted from fresh sugar beet under different conditions using an experimental design. Carbohydrate Polymers. 49. 2002. pp. 145-153

[2] S. Yeoh, J. Shi, T.A.G. Langrish. Comparisons between different techniques for water-based extraction of pectin from orange peels. Desalination. 218. 2008. pp. 229-237

[3] P. Fellows. Food Processing Technology: Principles and practice. Cambridge: Woodhead Publishing Limited. 2009

[4] D. N. A. Zaidel, N. N. Zainudin, Y. M. M. Jusoh, I. I. muhamad. Extraction and characterization of pectin from Sweet potato (ipomoea batatas). PULP SOMChE \& RSCE. 2014

[5] C. D. May. Industrial pectins: Sources, production and applications. Carbohyd Polym. 12.1990). pp. 79-99

[6] A. G. J. Voragen, W. Pilnik, J. F. Thibault, M. A. V. Axelos, C. M. G. C Renard. "Pectins." In: Food Polysaccharide and Their Application. A. M. Stephen. Ed. New York. USA: Marcel Dekker. 1995. pp. 287-339.

[7] P. Sriamornsak. Chemistry of pectin and its pharmaceutical uses: A review. Silpakorn University International Journal 3. 2003. pp. 206-228

[8] P. shrivastava, R. Malyaviya. Source of Pectin Extraction and Its Application in Pharmaceutical Industry - An Overview. Indian Journal of Natural Products and Resources.Vol. 2 (1). 2011, pp. 10-18.

[9] A. Schieber, F. C. Stintzing, R. Carle. By-products of plant food processing as a source of functional compounds - recent developments. Trends Food Sci Technol. 12. 2001. pp. 401-413

[10] B. M. Yapo, K. L. Koffi. Extraction and characterization of highly gelling low methoxy pectin from cashew apple pomace. Foods 3(1). 2014. pp. 1-12

[11] C. M. Polesca de Feitas, R. D. Martins, M. M. D. S. Dias, J. S. D. R. Coimbra R. D C. Superbi de Sousa. Passion fruit by-product: process design of pectin production.International Journal of Research. GRANTHAALAYAH.8 (10).2020. pp. 58-69

[12] A. R. J. RANDRIAMPENOHAJA, C. A. RASOLOHERY, M RAKOTOVAO, J. R. E. RASOARAHONA. Influences of the $p H$, the liquid/solid ratio and the mixing of the wastes of mango, passion fruit and Bambara groundnut on the extraction yield of pectin. International Journal of Scientific and Research Publications. Volume 11, Issue 7. 2021. pp 226-235.

[13] A. Miyamoto. Extraction and Physicochemical Characterization of Pectin from sunflower Head Residues. J. Food Sci. 57(3). 1992. pp. 19-23.

[14] J. W. Gorman and J. A. Cornell. A note on model reduction for experiments with both mixture components and process variables. Techno-metrics. 24. 1982. pp. 243-247.

[15] J. Lawson. Design and Analysis of Experiments with $R$, CRC Press, ISBN Number-13: 978-1-4987-2848-5 (eBook - PDF). 2015. pp. 447-502

[16] B. Koubala, , L. I. Mbome, G. Kansci, F. T. Mbiapo, M. J. Crepeau, J.F. Thibault, and M.C. Ralet. Physico-chemical Properties of Pectins from Ambarella Peels Obtained Using Different Extraction Conditions. Food Chemistry 106. 2008. pp. 1202-1207.

[17] H. Scheffe. Simplex-centroid designs for experiments with mixtures. Journal of Royal Statistical Society,Series B, 25. 1963. pp. 235-263.

[18] H. Mohamed. Extraction and Characterization of Pectin from Grapefruit Peels. MOJ Food process Technol 2(1): 00029. 2016

[19] B. M. Yapo. Pectin quantity, composition and physicochemical behavior as influenced by the purification process. Food Research International. 42. 2009. pp. 1197-1202 
[20] H. S. Owens, R. M. McCready, A. D.Shepherd, S. H.Schultz, E. L.Pippen, H. A.Swenson, J. C. Miers, R. F. Erlandsen and W. D. Maclay, Methods used at Western Regional Research Laboratory for Extraction and Analysis of Pectic Materials, AIC-340, Western Regional Research Laboratory, Albany, California. 1952.

[21] S. Ranganna S. Handbook of Analysis of Quality Control for Fruit and Vegetable Products. Tata McGraw-Hill Publ. Co. New Delhi. India. 1986

[22] M. H. Norziah, E. O.Fang, and A. A. Karim. "Extraction and characterization ofpectin from pomelo fruit peels." In Gums and Stabilisers for the food industry. G. P. P.A. Williams Ed.. Cambridge, UK: The Royal Society of Chemistry. 10. 2000. pp. 26-360.

[23] S. Mohamed, and Z. Hasan, Extraction and Characterization of Pectin from Various Tropical Agrowastes. ASEAN Food Journal. 10. 1995. pp. 43-50

[24] T. Sudha, G. Divya, J. Sujaritha, P. Duraimurugan. Review of experimental design in analytical chemistry, Indo American Journal of Pharmaceutical Research. 2017.

[25] J. Cornell, John. Experiments with Mixtures: Designs, Models, and the Analysis of Mixture Data, John Wiley \& Sons, Inc. New York. 2002.

[26] S. Faetherstone. Jams, jellies, and related products. In A Complete Course in Canning and Related Processes. 14 ed. vol 3. Woodhead Publishing. Food Science, Technology and Nutrition. 2016. pp 313-349.

[27] International Pectin Producers Association. What Is Pectin. http://www.ippa.info/history_of_pektin.htm. 2002. Accessed 28th February 2019.

[28] JECFA. Joint FAO/WHO Expert Committee on Food Additive. Compendium of food additive specifications. In 82nd Meeting 2016. Vol 19. Rome, Italy. 2016.

[29] C. Gan, and A. A. Latiff. Extraction of antioxidant pectic-polysaccharide from mangosteen (Garcinia mangostana) rind: optimization using response surface methodology. Carbohydrate, Polymers. 83. 2011. pp. 600-607.

[30] E. C. Arollado, RL. F. Ramirez, R. A. M. Manalo, G. L. T. Dela Torre, K. M. G. Ponsaran1 S. M. M. Salvador, and M. P. F. Siocson. Optimization of the Isolation and Purification Method of Pharmaceutical Grade Pectin from Pomelo Fruit Peels (Citrus maxima Merr. [Family Rutaceae]). ACTA MEDICA PHILIPPINA VOL. 52 NO. 4. 2018. pp 356-359.

[31] A. K. M. Azad , M. A. Ali, M. S. Aktar, M. J. Rahman, and M. Ahmed. Isolation and Characterization of Pectin Extracted from Lemon Pomace during Ripening, Journal of Food and Nutrition Sciences. 2. 2014. pp 30-35

[32] K. Nahar, M. Z. Haque, K. Nada, M. N. Uddin, M. Abdullah Al-Mansur, N. Khatun and S. A. Jabin, Pectin from ripe peels of mango cultivars. Bangladesh J. Sci. Ind. Res. 52(3). 2017. pp. 229-238.

[33] U. Altaf, G. Immanuel, F. Iftikhar. Extraction and characterization of pectin derived from papaya (Carica papaya Linn.). PEELVolume 3. Issue 4. 2015. pp. 2395-4752.

[34] W. E. Devi, R. N. Shukla, K. L. Bala, A. Kumar; A. A. Mishra, K. C. Yadav. Extraction of Pectin from Citrus Fruit Peel and Its Utilization in Preparation of Jelly. International Journal of Engineering Research \& Technology (IJERT) ISSN: 2278-0181 Vol. 3 Issue 5. 2014

[35] R. Nazaruddin. (2011), Effect of ammonium oxalate and acetic acid at several extraction time and $\mathrm{pH}$ on some physicochemical properties of pectin from cocoa husks (Theobroma cacao). African Journal of Food Scienc. 5. 2011. pp. $790-798$.

[36] Food Chemical Codex, 4th Ed. National Academy Press, Washington D.C. 1996.

[37] S.M. Norazelina, and R. Nazarrudin. Extraction and characterization of pectin from dragonfruit (Hylocereus polyrrhizus) using various extraction conditions. Malaysia: Sains Malaysiana 41(1). 2011. pp. 41-45.

[38] A. G. Mahala, A. A. A. Mohammed. Nutritive evaluation of bambara groundnut (Vigna subterranean) pods, seeds and hull as animal feeds. J Appl Sci Res. 6(5). 2010. pp. 383-386.

[39] K. A. T. Castillo-Israel, S. F. Baguio, M. D. B. Diasanta, R. C. M. Lizardo, E. I. Dizon, M. I. F. Mejico. Extraction and characterization of pectin from Saba banana [Musa 'saba' (Musa acuminata x Musa balbisiana)] peel wastes: A preliminary study. International Food Research Journal. 22(1). 2015. pp. 190-195.
[40] P. A. E. Rose, and D. Abilasha. Extraction and characterization of pectin from lemon peel. International Journal of Advanced B48:B68Science and Research. Volume 1. Issue 12. 2016. pp. 12-15.

[41] S. R. Omar, N. A. M. D. Hamsan, M. N. Abdullah. Waste to wealth: optimizing novel pectin acid extraction from honeydew (cucumis melo l. var. inodorous) peels as a potential halal food thickener. MOJ Food Process Technol. 8(1) 2020. pp. 13-17.

[42] B. M. Yapo. On the colorimetric-sulfuric acid analysis of uronic acids in food materials: potential sources of discrepancies in data and how to circumvent them. Food Analytical Methods, 5(2). 2012. pp.195-215.

[43] D. Constenla and J. E. Lozano. Kinetic model of pectin demethylation. Latin Am Appl Res. 33. 2003. pp. 91-95.

[44] A. Madhav and P. B. Pushpalatha. Characterization of Pectin Extracted From Different Fruit Wastes, Journal of Tropical Agriculture 40. 2000. pp. 53-55.

[45] R. H. Walter. The chemistry and technology of pectin, Food Science and Technology-A series of monographs. Academic Press, New York. 1991

[46] G. A. Morris, T/ J. Foster and S. E. Harding. The effect of the degree of esterification on the hydrodynamic properties of citrus pectin. Food Hydrocolloid 14. 2000. pp. 227-235.

[47] S. M. Cardoso, M. A. Coimbra and J. A. Lopes da Silva. Temperature dependence of the formation and melting of pectin-Ca2 ${ }^{+}$networks: a rheological study. Food Hydrocolloid. 17. 2003. pp. 801-807.

[48] R. Gnanasambandam, and A. Proctor. Determination of pectin degree of esterication by diffuse reflectance Fourier transform infrared spectroscopy. Food Chemistry. 68. 2000. pp. 327-332.

[49] S. Q. Liew, N. L. Chin, Y. A. Yusof. Extraction and Characterization of Pectin from Passion Fruit Peels Agriculture and Agricultural Science Procedia 2. 2014. pp. $231-236$.

[50] E. R. Pinheiro, I. M. D. A. Silva, L. V. Gonzaga, E. R. Amante, R. F. Teo'filo , M. M.C. Ferreira, R. D.M.C. Amboni, Optimization of extraction of highester pectin from passion fruit peel (Passiflora edulis flavicarpa) with citric acid by using response surface methodology. Bioresource Technology 99. 2008. pp. 5561-5566.

[51] E. Kliemann et al. Optimisation of pectin acid extraction from passion fruit peel (Passiflora edulis flavicarpa) using response surface methodology. IJFST. 44. 2009. pp. 476-483

[52] K. Woo, Y. Y. Chong, S. K. Li Hiong, and P. Y. Tang. Pectin Extraction and Characterization from Red dragon Fruit (Hylocerus polyrhyzuz): A Preliminary Study, J Biol Sci. 10. 2010. pp. 631-636.

\section{AUTHORS}

First Author - RANDRIAMPENOHAJA A. R. Jens. College of Agricultural Sciences (Dept. Food and Agricultural Industries) and Doctoral School for Engineering of Processes and Industrial, Agricultural and Food Systems, University of Antananarivo. Assistant Professor at Ambositra Institute of Technology (Dept. of Food Process and craft Industries). jensfenohaja@yahoo.fr. Second Author - RASOLOHERY Claudine A. Plant-Health Laboratory, Fianarantsoa. Faculty of Science, University of Fianarantsoa, Madagascar. carasolohery@gmail.com Third Author - RAKOTOVAO Marcelle. Chemistry and Natural Products Laboratory, Faculty of Science, University of Antananarivo, Madagascar. rakmarcelleraza@gmail.com Correspondence Author - RASOARAHONA Jean R. E. Professor at the College of Agricultural Sciences (Dept. Food and Agricultural Industries) and Doctoral School for Engineering of Processes and Industrial, Agricultural and Food Systems, Madagascar. jeanras@moov.mg +2613311318 82 or +261342936607 